\title{
Association between PCOS and autoimmune thyroid disease: a systematic review and meta-analysis
}

\author{
Mírian Romitti ${ }^{1, *}$, Vitor C Fabris ${ }^{2, *}$, Patricia K Ziegelmann³, Ana Luiza Maia ${ }^{1}$ and Poli Mara Spritzer ${ }^{2}$ \\ ${ }^{1}$ Thyroid Unit, Endocrine Division, Hospital de Clínicas de Porto Alegre, Universidade Federal do Rio Grande do Sul, Porto Alegre, RS, Brazil \\ ${ }^{2}$ Gynecological Endocrinology Unit, Endocrine Division, Hospital de Clínicas de Porto Alegre, and Department of Physiology, Universidade Federal do Rio \\ Grande do Sul, Porto Alegre, RS, Brazil \\ ${ }^{3}$ Postgraduate Program in Epidemiology and Department of Statistics, Institute of Mathematics, Universidade Federal do Rio Grande do Sul, Porto \\ Alegre, RS, Brazil \\ Correspondence should be addressed to P M Spritzer: spritzer@ufrgs.br \\ *(M Romitti and V C Fabris contributed equally to this work)
}

\begin{abstract}
Polycystic ovary syndrome (PCOS) is the most prevalent endocrine disorder affecting women of reproductive age. PCOS has been associated with distinct metabolic and cardiovascular diseases and with autoimmune conditions, predominantly autoimmune thyroid disease (AITD). AITD has been reported in $18-40 \%$ of PCOS women, depending on PCOS diagnostic criteria and ethnicity. The aim of this systematic review and metaanalysis was to summarize the available evidence regarding the likelihood of women with PCOS also having AITD in comparison to a reference group of non-PCOS women. We systematically searched EMBASE and MEDLINE for non-interventional case control, cross-sectional or cohort studies published until August 2017. The Ottawa-Newcastle Scale was used to assess the methodological quality of studies. Statistical meta-analysis was performed with R. Thirteen studies were selected for the present analysis, including 1210 women diagnosed with PCOS and 987 healthy controls. AITD was observed in 26.03 and $9.72 \%$ of PCOS and control groups respectively. A significant association was detected between PCOS and chance of AITD (OR=3.27, 95\% Cl 2.32-4.63). Notably, after geographical stratification, the higher risk of AITD in PCOS women persisted for Asians (OR=4.56, 95\% Cl 2.47-8.43), Europeans (OR=3.27, 95\% Cl 2.07-5.15) and South Americans (OR $=1.86,95 \% \mathrm{Cl} 1.05-3.29)$. AIDT is a frequent condition in PCOS patients and might affect thyroid function. Thus, screening for thyroid function and thyroidspecific autoantibodies should be considered in patients with PCOS even in the absence of overt symptoms. This systematic review and meta-analysis is registered in PROSPERO under number CRD42017079676.
\end{abstract}

Key Words
- PCOS
- autoimmune thyroid
disease
- TSH
- systematic review
- meta-analysis

Endocrine Connections (2018) 7, 1158-1167

\section{Introduction}

Polycystic ovary syndrome (PCOS) is an endocrine disorder affecting women of reproductive age. The worldwide prevalence of PCOS ranges from 9 to $19.9 \%$, depending on population characteristics and diagnostic criteria $(1,2,3,4,5)$. Diagnosis of this complex multifactorial disease is based on the presence of two out of three of the following: clinical and/or biochemical androgen excess, anovulation and polycystic ovaries on pelvic ultrasound. The mechanisms underlying individual susceptibility to PCOS include hyperinsulinemia, disruption of the https://ec.bioscientifica.com

https://doi.org/10.1530/EC-18-0309 (c) 2018 The authors Published by Bioscientifica Ltd

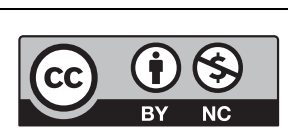

This work is licensed under a Creative Commons Attribution-NonCommercial 4.0 International License. 
hypothalamic-pituitary-gonadal axis, dysregulation of ovarian steroidogenesis, low-grade chronic inflammation (6) and genetic and environmental factors $(7,8,9)$. PCOS has also been associated with type 2 diabetes, insulin resistance, obesity, dyslipidemia, hypertension and metabolic syndrome, suggesting a contribution of the syndrome to cardiovascular risk $(10,11,12,13,14,15)$.

The association between inflammation and autoimmunity in women with PCOS has been extensively discussed in recent years (16). Chronic lowgrade inflammation might be a relevant connecting link between obesity and metabolic manifestations in PCOS $(6,17)$. After detecting antiovarian autoantibodies localized to the granulosa cells in women with PCOS, Van Gelderen et al. suggested a role of stimulating ovarian antibodies in PCOS pathophysiology (18). However, the concept of an autoimmune etiology is not supported by other studies describing similar prevalence of antiovarian autoantibodies in women with PCOS and controls (19), leading to the proposal of systemic immune activation by nonorgan-specific autoantibodies in PCOS (20). This could explain the recurrent association between PCOS and autoimmune diseases $(21,22)$ and especially autoimmune thyroid diseases (AITD), the most common form of autoimmune disorder, with an estimated prevalence of $5 \%(23,24,25)$.

AITD results from a dysregulation of the immune system that produces an immune attack with consequent chronic inflammation of the thyroid gland. It is classified as a $\mathrm{T}$ cell-mediated organ-specific autoimmune disorder (26). Affected individuals are usually positive for thyroid peroxidase (TPOAbs) and/or thyroglobulin (TgAbs) antibodies, with a typical hypoechogenic pattern at ultrasonography $(27,28)$. AITD is regarded as the most frequent cause of hypothyroidism in young women. Nevertheless, detectable antibodies may be observed for years without overt thyroid dysfunction. Hence, AITD often goes unnoticed until the onset of hypothyroidism later in life (29). Furthermore, a recent meta-analysis has demonstrated that the presence of subclinical hypothyroidism in PCOS women produces mild metabolic abnormalities, affecting the levels of highdensity lipoprotein (HDL), triglyceride and homeostatic model assessment for insulin resistance (HOMA-IR) (30).

To date, several studies evaluating the association between AITD and PCOS have been published without reaching a clear conclusion. A previous meta-analysis assessed the relationship between PCOS and some of its features and thyroiditis. That article included six studies, three of which were meta-analyzed to assess the prevalence of thyroiditis among women with PCOS. The results suggested a higher incidence of thyroiditis in PCOS than those in controls (31). Therefore, the aim of this systematic review and meta-analysis was to summarize and update the available evidence regarding the likelihood of women with PCOS also having AITD in comparison to a reference group of women without PCOS.

\section{Methods}

\section{Search strategy and study selection}

EMBASE and MEDLINE databases were searched for studies published until August 2017. No other limits except for the end date were established for the search. The protocol for this systematic review and meta-analysis is registered in PROSPERO (http://www.crd.york.ac.uk/ PROSPERO/) under number CRD42017079676. Medical subject headings (MeSH) used in the search are presented as supplementary data (see section on supplementary data given at the end of this article).

The research question was developed using the PICOS strategy: the population (P) was defined as women in menacme; the intervention (I) was defined as diagnosis of PCOS; the comparison group (C) corresponded to women without PCOS; the outcome $(\mathrm{O})$ was defined as autoimmune thyroid disease (AITD) and the study design (S) was defined to include non-interventional case control, cross-sectional or cohort studies. This review had no year or language restrictions.

In case multiple reports of the same study were identified, the most complete report was chosen. If the abstracts did not provide enough information about inclusion and exclusion criteria, the full text was retrieved for evaluation.

\section{Data extraction and quality control}

Two investigators ( $\mathrm{M}$ R and $\mathrm{V}$ C F) independently reviewed the titles and abstracts of all articles identified in the initial search to assess eligibility of the studies for inclusion in this systematic review and meta-analysis. The selected articles were read in full for confirmation of eligibility and data extraction. In case of disagreement, a third reviewer (P M S) was consulted. The following information was extracted from each study: name of first author, publication year, country, number of subjects in case and control groups, age, BMI and number of patients with AITD (according to the diagnostic criteria for AITD

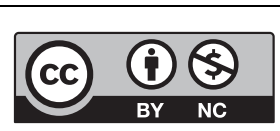

This work is licensed under a Creative Commons Attribution-NonCommercial 4.0 International License. 
described in the study) and serum levels of thyroidstimulating hormone (TSH).

The Newcastle-Ottawa Scale (NOS) (Retrieved August, 2017, from: www.ohri.ca/programs/clinical_ epidemiology/oxford.asp) was used to assess the quality of the studies included in the meta-analysis. The NOS uses a 'star system' to judge the included studies in three broad perspectives: selection of the study groups, comparability of those groups and ascertainment of outcome of interest.

\section{Statistical analysis}

Odds ratios (ORs) were used to measure the association between diagnostic status (PCOS or healthy) and AITD. ORs were pooled by the Mantel and Haenszel method using a random effects model with Der Simonian and Laird's estimator. The Mantel-Haenszel method is more appropriate when using OR because it provides interval estimates with greater precision than those produced by the conventional inverse variance method. $I^{2}$ statistics and the Cochran $\mathrm{Q}$ test were used to assess heterogeneity among studies. Subgroup meta-analysis (considering region of the study) and meta-regression (considering year of publication and total sample size) were also performed to investigate the heterogeneity among studies. All statistical tests were two-tailed. Significance was defined as $P<0.05$. Statistical analyses were performed with $\mathrm{R}$ version 3.2.1.

\section{Results}

\section{Study selection}

The primary literature search identified 811 articles. After title and abstract screening, 20 studies were retrieved for full-text review. Of these, three were excluded because the full-text version could not be retrieved. A fourth study was excluded for not having a full text version (only a conference abstract had been published). Finally, three additional studies were excluded because data regarding the number or percentage of AITD individuals in each study group (PCOS and controls) was not provided. Therefore, 13 studies were included in the systematic review and meta-analysis (Fig. 1).

\section{Characteristics of the included studies}

A summary of the main characteristics of the 13 studies included in the systematic review and meta-analysis is described in Table 1. Seven studies focused on Asian populations: three were performed with Turkish women $(32,33,34)$, three with women from India $(35,36,37)$ and one with Chinese women (38). Four studies in Europe evaluated German (39), Italian (40), Bulgarian (41) and Slovakian (42) women. Another two studies were performed in Brazilian (43) and Argentinian (44) populations. All studies employed the 2003 Rotterdam criteria for diagnosis of PCOS. AITD diagnosis was based on the criteria defined in each study. Regarding design, there were nine cross-sectional studies $(32,33,34,37,39,40$, $41,42,43)$ and four case-control studies $(35,36,38,44))$. Population size ranged from 22 to 175 patients, totaling 1210 women with PCOS and 987 healthy controls. In nine studies, age-matched women were selected for inclusion in the comparison group $(32,34,37,39,40,42,44)$, whereas three studies included healthy age-matched and BMI-matched controls $(33,38,41)$. In one study, controls were described only as healthy women, without further specification (43). The mean age of PCOS participants ranged from 22 to 30.23 years, vs 20.5 to 33.5 years in comparison groups. Mean BMI ranged from 24.6 to $34.8 \mathrm{~kg} / \mathrm{m}^{2}$ in PCOS and 21.3 to $29.2 \mathrm{~kg} / \mathrm{m}^{2}$ in comparison groups (Table 1). NOS score was 9 in six studies $(33,37$, $38,40,41,44), 8$ in six studies $(32,34,35,36,39,42)$ and 7 in one study (43) (Table 2).

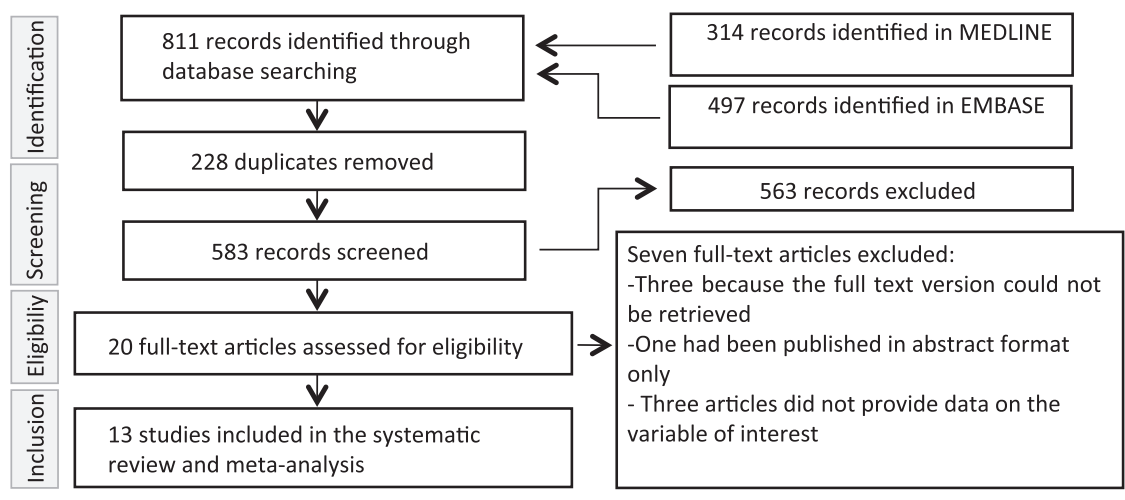

Figure 1

PRISMA flow diagram of the study selection process. 


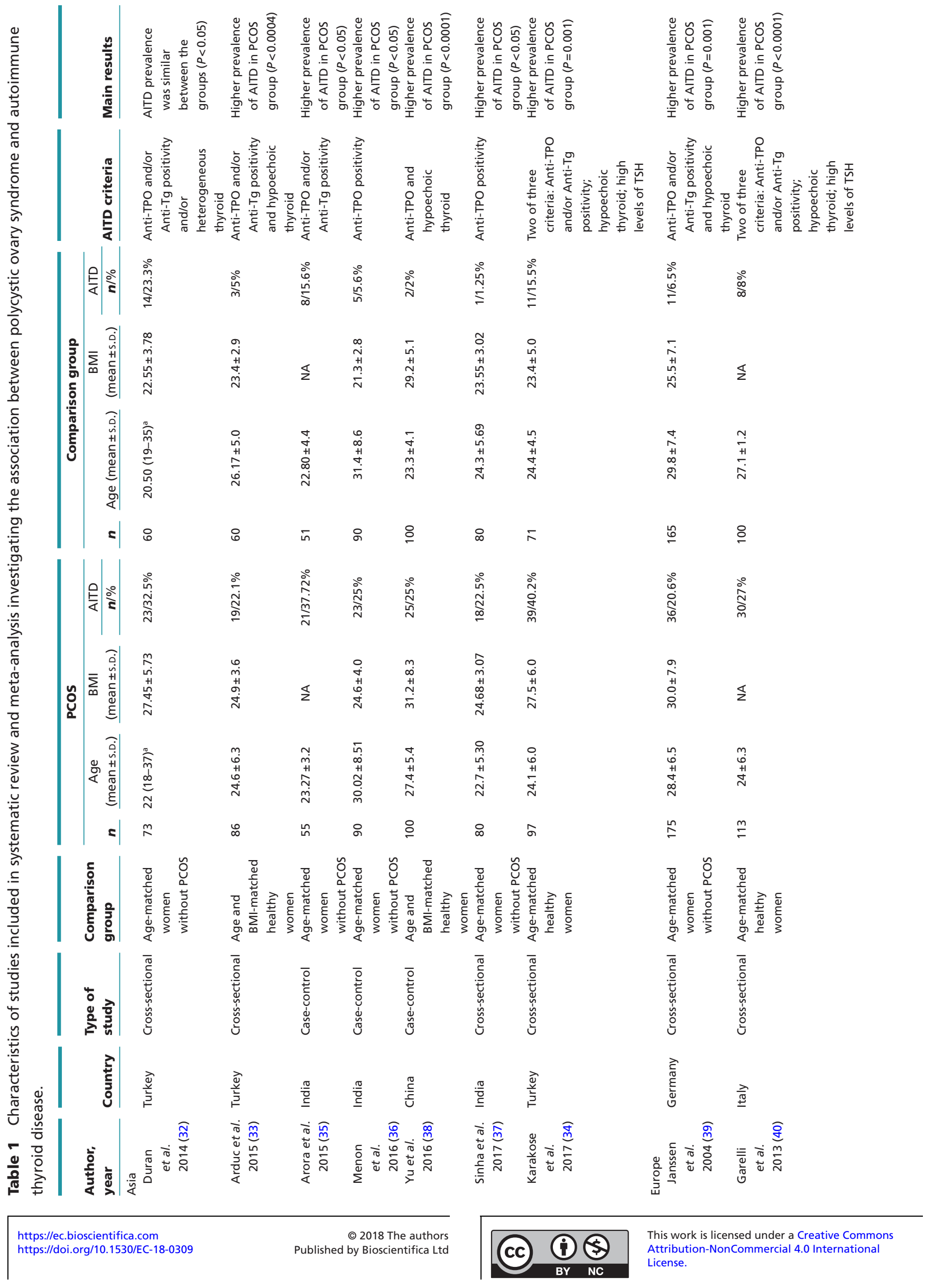




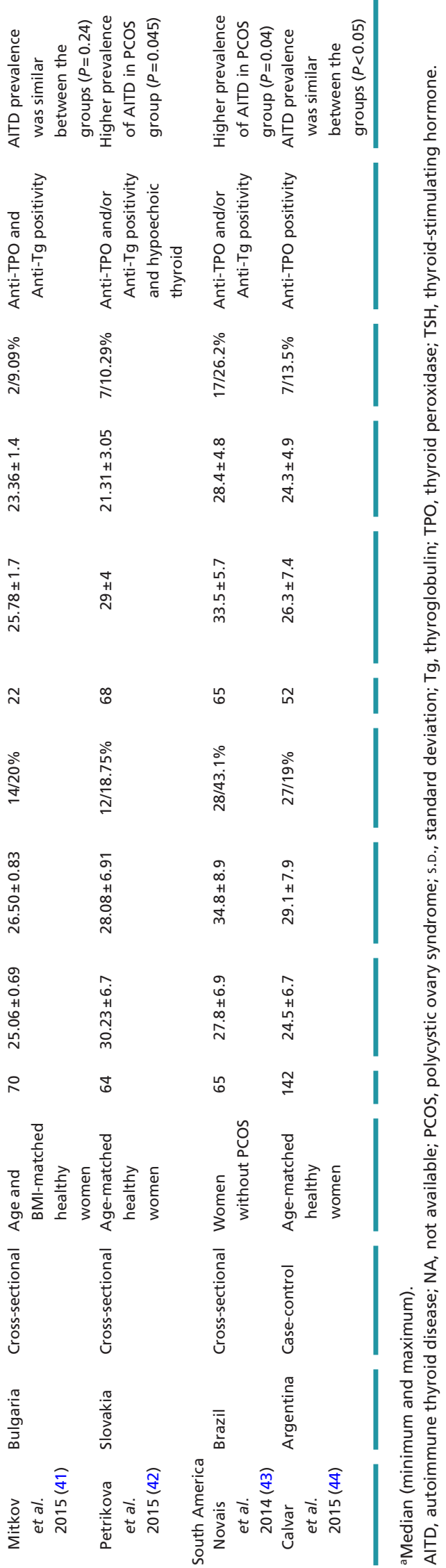

https://ec.bioscientifica.com https://doi.org/10.1530/EC-18-0309
() 2018 The authors Published by Bioscientifica Ltd
Main results

AITD was detected in 315 (26.03\%) out of 1210 PCOS women and in $96(9.72 \%)$ out of 987 healthy controls. Geographical stratification revealed the presence of AITD in $28.91,21.8$ and $26.57 \%$ of PCOS patients and in 8.59 , 7.82 and $20.51 \%$ of healthy women from Asia, Europe and South America respectively. Figure 2 shows the individual and pooled odds ratios (ORs) for associations between PCOS and risk of AITD. Overall, a significant association was observed between PCOS and the presence of AITD $(\mathrm{OR}=3.27,95 \%$ CI 2.32-4.63; $P<0.0001)$. After geographical stratification, the higher chance of AITD in PCOS persisted for Asians (OR=4.56, 95\% CI 2.47-8.43), Europeans $(\mathrm{OR}=3.27$, 95\% CI 2.07-5.15) and South Americans (OR=1.86, 95\% CI 1.05-3.29); however, the difference between subgroups was not statistically significant $(P=0.0987)$.

Between-study heterogeneity was $I^{2}=39 \%(P=0.07)$. Subgroup analysis by geographic region accounted for $10.81 \%$ of this heterogeneity, although statistical significance was not reached $(P=0.20)$. Meta-regression showed that neither year of publication nor total sample size contributed to the observed heterogeneity $(<0.1 \%)$ (Supplementary Figure 1).

Table 3 describes TSH levels in PCOS and comparison groups. Heterogeneous findings were obtained: six studies demonstrated higher TSH levels in PCOS women compared to the control group $(P<0.05)(33,37,38,39$, $43,44)$. Conversely, five studies did not find a significant difference $(P>0.05)(32,34,35,36,41)$ between women with PCOS and controls, and one study did not provide TSH data (40). Further analyses were not performed because of the limited amount of data regarding clinical characteristics of PCOS patients with or without AITD in the studies that were selected for analysis.

\section{Discussion}

In the present systematic review and meta-analysis, PCOS patients from different populations presented higher likelihood of AIDT compared to controls (OR=3.27, 95\% CI 2.32-4.63). Of note, higher risk of AIDT was detected in Asian populations ( $\mathrm{OR}=4.56$, 95\% CI 2.47-8.43). However, such differences among the regions were not explained by specific risk factors. Also, there is evidence that thyroid autoimmunity occurs across the world without geographic differences (45). In this sense, the differences in AIDT frequency among the studies could be

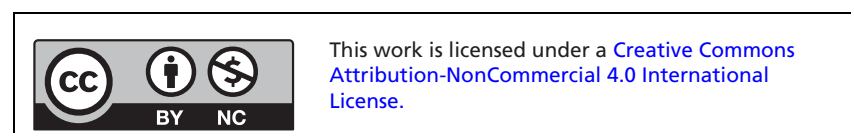


Table 2 Newcastle-Ottawa Scale for assessing the quality of nonrandomized studies.

\begin{tabular}{l} 
Author, year \\
\hline Duran et al. $2014(31)$ \\
Arduc et al. 2015 (32) \\
Arora et al. 2015 (34) \\
Menon et al. 2016 (35) \\
Yu et al. 2016 (37) \\
Sinha et al. 2017 (36) \\
Karakose et al. 2017 (33) \\
Janssen et al. 2004 (38) \\
Garelli et al. 2013 (39) \\
Mitkov et al. 2015 (40) \\
Petrikova et al. 2015 (41) \\
Novais et al. 2014 (42) \\
Calvar et al. 2015 (43)
\end{tabular}

\begin{tabular}{l}
\hline \\
Selection \\
$\star \star \star \star$ \\
$\star \star \star \star$ \\
$\star \star \star \star$ \\
$\star \star \star \star$ \\
$\star \star \star \star$ \\
$\star \star \star \star$ \\
$\star \star \star \star$ \\
$\star \star \star \star$ \\
$\star \star \star \star$ \\
$\star \star \star \star$ \\
$\star \star \star \star$ \\
$\star \star \star \star$ \\
$\star \star \star \star$
\end{tabular}

attributed to variations in AIDT diagnostic criteria and in the size of studied groups.

While thyroid disorders and PCOS are among the most common endocrine conditions in the general

Score (Stars)
Comparability
$\star$
$\star \star$
$\star$
$\star$
$\star \star$
$\star$
$\star$
$\star \star$
$\star \star$
$\star$
$\star \star$

Outcome
$\star \star \star$
$\star \star \star$
$\star \star \star$
$\star \star \star$
$\star \star \star$
$\star \star \star$
$\star \star \star$
$\star \star \star$
$\star \star \star$
$\star \star \star$
$\star \star \star$
$\star \star \star$
$\star \star \star$

Total score

\begin{tabular}{c} 
Total score \\
\hline 8 \\
9 \\
8 \\
8 \\
9 \\
9 \\
8 \\
8 \\
9 \\
9 \\
8 \\
7 \\
9
\end{tabular}

population, the pathophysiological pathway connecting these two disorders has not been clearly established. The mechanism driving the autoimmune attack to the thyroid is complex and includes predominantly

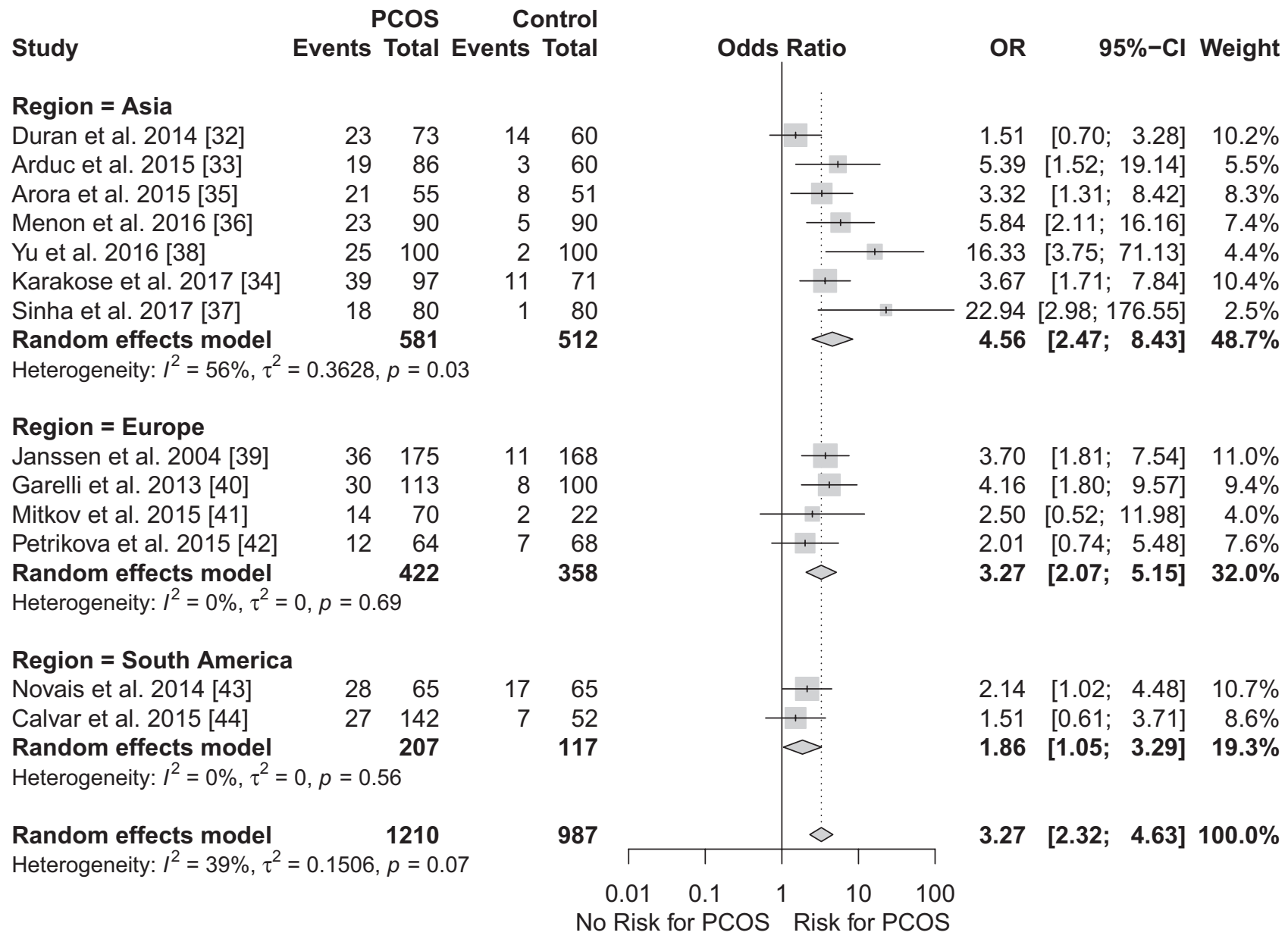

Figure 2

Forest plot showing individual and pooled odds ratios for presence of AITD in women with PCOS in different populations.

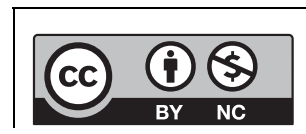

This work is licensed under a Creative Commons Attribution-NonCommercial 4.0 International License. 
genetic, gender-associated and environmental factors such as iodine supply, drugs, infections and chemicals $(26,46)$. Likewise, the etiology of PCOS is suggested to involve genetic, ovarian-related and other hormonal and metabolic factors such as insulin resistance/ compensatory hyperinsulinemia (47). However, a common genetic background has not yet been established.

Abnormal interactions between thyrocytes, antigenpresenting cells and $\mathrm{T}$ cells, along with environmental and hormonal factors are found in thyroid disease, producing disturbances in the normal balance between type 1 helper (TH1) and type 2 helper (TH2) lymphocyte immune response. More specifically, TH1-mediated autoimmunity leads to the lysis of thyrocytes and autoimmune hypothyroidism (Hashimoto's thyroiditis), whereas stimulatory $\mathrm{TH} 2$ responses against the $\mathrm{TSH}$ receptor lead to hyperthyroidism (Grave's disease) (48). PCOS is characterized by androgen excess, which has been shown to be associated with reduction of most

Table 3 Studies comparing TSH levels in PCOS and control groups.

\begin{tabular}{|c|c|c|c|}
\hline \multirow[b]{2}{*}{ Author, year } & \multicolumn{2}{|c|}{ TSH (mean \pm S.D.) } & \multirow[b]{2}{*}{$P$ value } \\
\hline & PCOS & Comparison group & \\
\hline $\begin{array}{l}\text { Duran et al. } \\
2014 \text { (32) }\end{array}$ & $2.09(0.67-16.51)^{\mathrm{a}}$ & $1.96(0.01-7.08)^{a}$ & 0.397 \\
\hline $\begin{array}{l}\text { Arduc et al. } \\
2015 \text { (33) }\end{array}$ & $2.9(0.20-17.9)^{a}$ & $1.8(0.31-5.4)^{\mathrm{a}}$ & 0.037 \\
\hline $\begin{array}{c}\text { Arora et al. } \\
2015 \text { (35) }\end{array}$ & $3.17 \pm 2.74$ & $2.98 \pm 2.18$ & 0.70 \\
\hline $\begin{array}{l}\text { Menon et al. } \\
2016 \text { (36) }\end{array}$ & $5.99 \pm 1.8$ & $8.09 \pm 2.4$ & 0.50 \\
\hline $\begin{array}{l}\text { Yu et al. } \\
2016(38)\end{array}$ & $5.11 \pm 22.7$ & $2.9 \pm 3.2$ & $<0.001$ \\
\hline $\begin{array}{c}\text { Sinha et al. } \\
2017 \text { (37) }\end{array}$ & $4.547 \pm 2.66$ & $2.67 \pm 3.11$ & $<0.001$ \\
\hline $\begin{array}{l}\text { Karakose } \\
\text { et al. } \\
2017 \text { (34) }\end{array}$ & $2.4 \pm 1.2$ & $2.0 \pm 1.0$ & 0.243 \\
\hline $\begin{array}{l}\text { Janssen et al. } \\
2004 \text { (39) }\end{array}$ & $2.0 \pm 1.0$ & $1.4 \pm 0.6$ & $<0.001$ \\
\hline $\begin{array}{c}\text { Garelli et al. } \\
2013(40)\end{array}$ & NA & NA & NA \\
\hline $\begin{array}{l}\text { Mitkov et al. } \\
2015(41)\end{array}$ & $2.46 \pm 0.25$ & $1.73 \pm 0.11$ & $>0.05$ \\
\hline $\begin{array}{l}\text { Petrikova } \\
\text { et al. } \\
2015 \text { (42) }\end{array}$ & $2.37 \pm 1.46$ & $2.37 \pm 1.46$ & 0.937 \\
\hline $\begin{array}{l}\text { Novais et al. } \\
2014 \text { (43) }\end{array}$ & $2.9 \pm 1.8$ & $2.2 \pm 1.2$ & 0.013 \\
\hline $\begin{array}{c}\text { Calvar et al. } \\
2015 \text { (44) }\end{array}$ & $3.4 \pm 2.8$ & $1.8 \pm 0.9$ & $<0.001$ \\
\hline
\end{tabular}

immune system elements, enhancement of T suppressor cell activity, promotion of TH1 response and activation of CD8C (49). In addition, progesterone levels may inhibit macrophage proliferation, IL6 synthesis and peripheral antibody production (50). Also, in vivo and in vitro data indicate that progesterone has some capacity to suppress CD4+T cell proliferation and TH1 response (51). Indeed, PCOS women often present anovulatory cycles with low luteal phase progesterone levels and higher estrogen-to-progesterone ratio, which may increase their susceptibility to autoimmune disorders. This increased susceptibility may be due, at least in part, to the stimulatory action of estrogens on the immune system $(39,50)$. In turn, while studies suggest that androgens could provide protection against autoimmune disease, androgen influence on the immune system at the levels observed in PCOS is probably insufficient to prevent autoimmunity (46).

High levels of circulating IFN- $\gamma$-inducible protein 10 (IP-10/CXCL10) have been shown in patients with AITD, especially in association with a hypoechoic ultrasonographic pattern, which is a sign of a more severe lympho-monocytic infiltration and hypothyroidism (52). In fact, CXCL10 has been suggested as a marker of a stronger and more aggressive inflammatory response in the thyroid, subsequently leading to thyroid destruction and hypothyroidism (26). Interestingly, a recent study has shown that serum CXCL10 concentrations are increased in women with PCOS, which appears to be correlated with the inflammatory and insulin resistance status of PCOS (53).

The most obvious connection between thyroid diseases and PCOS seems to be an increase in BMI and insulin resistance found in both conditions. Increased BMI is very prevalent in women with PCOS, observed in 54-68\% of cases (54). Interestingly, although the pathophysiological mechanisms linking thyroid function and obesity have not been clearly established, evidence indicates that TSH is higher in people with high $\mathrm{BMI}(55,56)$. In contrast, recent data have shown that thyroid autoimmunity was not associated with BMI, though a connection with leptin and obesity has been suggested $(57,58)$. In the present meta-analysis, only 3 out of 13 studies included a BMImatched control group $(33,38,41)$, and higher BMI was found in PCOS compared to controls in most of the studies $(32,34,36,39,42,43,44)$. However, the three studies that stratified PCOS patients with and without AIDT did not observe significant differences in BMI, indicating a lack of association between BMI and AIDT in PCOS women $(39,40,44)$.

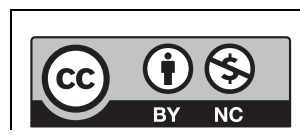

This work is licensed under a Creative Commons Attribution-NonCommercial 4.0 International License. 
According to large epidemiological surveys, AIDT is the most frequent cause of hypothyroidism in the adult population $(59,60,61,62)$. Clinical disease involves a variety of manifestations ranging from simple presence of thyroid antibodies (Tabs) in euthyroid patients to severe thyroid dysfunction. Most often, a euthyroid phase is followed by subclinical hypothyroidism ( $\mathrm{SCH})$, which slowly progresses to overt hypothyroidism (24). Subclinical hypothyroidism is frequently observed among women with PCOS, with an estimated prevalence range of 10-25\% (63). Regarding the impact of subclinical hypothyroidism on the clinical, hormonal or metabolic phenotype of women with PCOS, a recent meta-analysis has shown that the coexistence of SCH and PCOS leads to mild alterations in serum lipids and HOMA-IR, but not in hormone levels (SHBG, FSH, LH and their ratio). These mild changes are not clinically relevant in the short term. The long-term impact of these alterations regarding morbidity has not been established (30). In this sense, further studies searching for the prevalence of PCOS in women with autoimmune thyroid disease could add some additional information regarding the association between these two conditions.

One strength of the present systematic review and meta-analysis is that all studies considered the Rotterdam criteria to diagnose PCOS, ensuring a homogeneous PCOS population. One limitation concerns the fact that AITD diagnosis was assessed according to the authors' chosen criteria. Moreover, because the studies did not provide this information, we were unable to evaluate the differences in TSH levels between PCOS women with or without AIDT. The same was true for other clinical characteristics, which were not reported and therefore precluded further comparisons between the two groups. Another limitation is that, despite the absence of significant heterogeneity among studies from different geographical regions, there were limited data from Western European countries and the US. Due to these limitations, the present data should be interpreted with caution.

In conclusion, the present systematic review and meta-analysis provides evidence of higher prevalence of AITD in patients with PCOS compared to healthy controls. Therefore, physicians should consider screening for thyroid function and thyroid-specific autoantibodies at PCOS diagnosis, even in the absence of symptoms related with thyroid dysfunction.

\section{Supplementary data}

This is linked to the online version of the paper at https://doi.org/10.1530/ EC-18-0309.

\section{Declaration of interest}

The authors declare that there is no conflict of interest that could be perceived as prejudicing the impartiality of the research reported.

\section{Funding}

This work was supported by the Brazilian National Institute of Hormones and Women's Health/Conselho Nacional de Desenvolvimento Científico e Tecnológico (CNPq INCT 465482/2014-7) and Fundação de Amparo à Pesquisa do Rio Grande do Sul (FAPERGS INCT 17/2551-0000519-8).

\section{References}

1 March WA, Moore VM, Willson KJ, Phillips DI, Norman RJ \& Davies MJ. The prevalence of polycystic ovary syndrome in a community sample assessed under contrasting diagnostic criteria. Human Reproduction 201025 544-551. (https://doi.org/10.1093/ humrep/dep399)

2 Rotterdam ESHRE/ASRM-Sponsored PCOS consensus workshop group. REA-SPcw. Revised 2003 consensus on diagnostic criteria and long-term health risks related to polycystic ovary syndrome (PCOS). Human Reproduction 200419 41-47. (https://doi.org/10.1093/ humrep/deh098)

3 Okoroh EM, Hooper WC, Atrash HK, Yusuf HR \& Boulet SL. Is polycystic ovary syndrome another risk factor for venous thromboembolism? United States, 2003-2008. American Journal of Obstetrics and Gynecology 2012207 377.e1-377.e8. (https://doi. org/10.1016/j.ajog.2012.08.007)

4 Azziz R, Woods KS, Reyna R, Key TJ, Knochenhauer ES \& Yildiz BO. The prevalence and features of the polycystic ovary syndrome in an unselected population. Journal of Clinical Endocrinology and Metabolism 200489 2745-2749. (https://doi.org/10.1210/jc.2003032046)

5 Yildiz BO, Bozdag G, Yapici Z, Esinler I \& Yarali H. Prevalence, phenotype and cardiometabolic risk of polycystic ovary syndrome under different diagnostic criteria. Human Reproduction 201227 3067-3073. (https://doi.org/10.1093/humrep/des232)

6 Spritzer PM, Lecke SB, Satler F \& Morsch DM. Adipose tissue dysfunction, adipokines, and low-grade chronic inflammation in polycystic ovary syndrome. Reproduction 2015149 R219-R227. (https://doi.org/10.1530/REP-14-0435)

7 Jones MR, Chua AK, Mengesha EA, Taylor KD, Chen YD, Li X, Krauss RM, Rotter JI, Legro RS, Azziz R, et al. Metabolic and cardiovascular genes in polycystic ovary syndrome: a candidate-wide association study (CWAS). Steroids 201277 317-322. (https://doi. org/10.1016/j.steroids.2011.12.005)

8 Tsilchorozidou T \& Conway GS. Uterus size and ovarian morphology in women with isolated growth hormone deficiency, hypogonadotrophic hypogonadism and hypopituitarism. Clinical Endocrinology 200461 567-572. (https://doi.org/10.1111/j.13652265.2004.02126.x)

9 Jones MR \& Goodarzi MO. Genetic determinants of polycystic ovary syndrome: progress and future directions. Fertility and Sterility 2016 106 25-32. (https://doi.org/10.1016/j.fertnstert.2016.04.040)

10 Goverde AJ, van Koert AJ, Eijkemans MJ, Knauff EA, Westerveld HE, Fauser BC \& Broekmans FJ. Indicators for metabolic disturbances in anovulatory women with polycystic ovary syndrome diagnosed according to the Rotterdam consensus criteria. Human Reproduction 200924 710-717. (https://doi.org/10.1093/humrep/den433)

11 Wild RA, Carmina E, Diamanti-Kandarakis E, Dokras A, EscobarMorreale HF, Futterweit W, Lobo R, Norman RJ, Talbott E \& Dumesic DA. Assessment of cardiovascular risk and prevention of cardiovascular disease in women with the polycystic ovary 
syndrome: a consensus statement by the Androgen Excess and Polycystic Ovary Syndrome (AE-PCOS) Society. Journal of Clinical Endocrinology and Metabolism 201095 2038-2049. (https://doi. org/10.1210/jc.2009-2724)

12 Spritzer PM, Motta AB, Sir-Petermann T \& Diamanti-Kandarakis E. Novel strategies in the management of polycystic ovary syndrome. Minerva Endocrinologica 201540 195-212.

13 Wiltgen D \& Spritzer PM. Variation in metabolic and cardiovascular risk in women with different polycystic ovary syndrome phenotypes. Fertility and Sterility 201094 2493-2496. (https://doi.org/10.1016/j. fertnstert.2010.02.015)

14 Daan NM, Louwers YV, Koster MP, Eijkemans MJ, de Rijke YB, Lentjes EW, Fauser BC \& Laven JS. Cardiovascular and metabolic profiles amongst different polycystic ovary syndrome phenotypes: who is really at risk? Fertility and Sterility 2014102 1444-1451.e3. (https://doi.org/10.1016/j.fertnstert.2014.08.001)

15 Mykhalchenko K, Lizneva D, Trofimova T, Walker W, Suturina L, Diamond MP \& Azziz R. Genetics of polycystic ovary syndrome. Expert Review of Molecular Diagnostics 201717 723-733. (https://doi. org/10.1080/14737159.2017.1340833)

16 Sen A, Kushnir VA, Barad DH \& Gleicher N. Endocrine autoimmune diseases and female infertility. Nature Reviews Endocrinology 201410 37-50. (https://doi.org/10.1038/nrendo.2013.212)

17 Deligeoroglou E, Vrachnis N, Athanasopoulos N, Iliodromiti Z, Sifakis S, Iliodromiti S, Siristatidis C \& Creatsas G. Mediators of chronic inflammation in polycystic ovarian syndrome. Gynecological Endocrinology 201228 974-978. (https://doi.org/10.3109/09513590.2 012.683082)

18 van Gelderen CJ \& Gomes dos Santos ML. Polycystic ovarian syndrome. Evidence for an autoimmune mechanism in some cases. Journal of Reproductive Medicine 199338 381-386.

19 Petrikova J \& Lazurova I. Ovarian failure and polycystic ovary syndrome. Autoimmunity Reviews 201211 A471-A478. (https://doi. org/10.1016/j.autrev.2011.11.010)

20 Hefler-Frischmuth K, Walch K, Huebl W, Baumuehlner K, Tempfer C $\&$ Hefler L. Serologic markers of autoimmunity in women with polycystic ovary syndrome. Fertility and Sterility 201093 2291-2294. (https://doi.org/10.1016/j.fertnstert.2009.01.056)

21 Kaltsas GA, Korbonits M, Isidori AM, Webb JA, Trainer PJ, Monson JP, Besser GM \& Grossman AB. How common are polycystic ovaries and the polycystic ovarian syndrome in women with Cushing's syndrome? Clinical Endocrinology 200053 493-500. (https://doi. org/10.1046/j.1365-2265.2000.01117.x)

22 Moro F, De Simone C, Morciano A, Tropea A, Sagnella F, Palla C, Scarinci E, Teti A, Caldarola G, D'Agostino M, et al. Psoriatic patients have an increased risk of polycystic ovary syndrome: results of a cross-sectional analysis. Fertility and Sterility 201399 936-942. (https://doi.org/10.1016/j.fertnstert.2012.10.040)

23 Jacobson DL, Gange SJ, Rose NR \& Graham NM. Epidemiology and estimated population burden of selected autoimmune diseases in the United States. Clinical Immunology and Immunopathology 199784 223-243. (https://doi.org/10.1006/clin.1997.4412)

24 Vanderpump MP, Tunbridge WM, French JM, Appleton D, Bates D, Clark F, Grimley Evans J, Hasan DM, Rodgers H, Tunbridge F, et al. The incidence of thyroid disorders in the community: a twentyyear follow-up of the Whickham Survey. Clinical Endocrinology 199543 55-68. (https://doi.org/10.1111/j.1365-2265.1995. tb01894.x)

25 McGrogan A, Seaman HE, Wright JW \& de Vries CS. The incidence of autoimmune thyroid disease: a systematic review of the literature. Clinical Endocrinology 200869 687-696. (https://doi.org/10.1111/ j.1365-2265.2008.03338.x)

26 Antonelli A, Ferrari SM, Corrado A, Di Domenicantonio A \& Fallahi P. Autoimmune thyroid disorders. Autoimmunity Reviews 2015 14 174-180. (https://doi.org/10.1016/j.autrev.2014.10.016)
27 Dayan CM \& Daniels GH. Chronic autoimmune thyroiditis. New England Journal of Medicine 1996335 99-107. (https://doi. org/10.1056/NEJM199607113350206)

28 Cooper DS. Clinical practice. Subclinical hypothyroidism. New England Journal of Medicine 2001345 260-265. (https://doi. org/10.1056/NEJM200107263450406)

29 Poppe K, Velkeniers B \& Glinoer D. Thyroid disease and female reproduction. Clinical Endocrinology 200766 309-321. (https://doi. org/10.1111/j.1365-2265.2007.02752.x)

30 Pergialiotis V, Konstantopoulos P, Prodromidou A, Florou V, Papantoniou N \& Perrea DN. MANAGEMENT OF ENDOCRINE DISEASE: the impact of subclinical hypothyroidism on anthropometric characteristics, lipid, glucose and hormonal profile of PCOS patients: a systematic review and meta-analysis. European Journal of Endocrinology 2017176 R159-R66. (https://doi. org/10.1530/EJE-16-0611)

$31 \mathrm{Du}$ D \& Li X. The relationship between thyroiditis and polycystic ovary syndrome: a meta-analysis. International Journal of Clinical and Experimental Medicine 20136 880-889.

32 Duran C, Basaran M, Kutlu O, Kucukaydin Z, Bakdik S, Burnik FS, Aslan U, Erdem SS \& Ecirli S. Frequency of nodular goiter and autoimmune thyroid disease in patients with polycystic ovary syndrome. Endocrine 201549 464-469. (https://doi.org/10.1007/ s12020-014-0504-7)

33 Arduc A, Aycicek Dogan B, Bilmez S, Imga Nasiroglu N, Tuna MM, Isik S, Berker D \& Guler S. High prevalence of Hashimoto's thyroiditis in patients with polycystic ovary syndrome: does the imbalance between estradiol and progesterone play a role? Endocrine Research 201540 204-210. (https://doi.org/10.3109/07435800.2015.1015730)

34 Karakose M, Hepsen S, Cakal E, Sayki Arslan M, Tutal E, Akin S, Unsal I $\&$ Ozbek M. Frequency of nodular goiter and autoimmune thyroid disease and association of these disorders with insulin resistance in polycystic ovary syndrome. Journal of the Turkish German Gynecological Association 201718 85-89. (https://doi.org/10.4274/jtgga.2016.0217)

35 Arora S, Sinha K, Kolte S \& Mandal A. Endocrinal and autoimmune linkage: evidences from a controlled study of subjects with polycystic ovarian syndrome. Journal of Human Reproductive Sciences 20169 18-22. (https://doi.org/10.4103/0974-1208.178636)

36 Menon M \& Ramachandran V. Antithyroid peroxidase antibodies in women with polycystic ovary syndrome. Journal of Obstetrics and Gynaecology of India 201767 61-65. (https://doi.org/10.1007/s13224016-0914-y)

37 Sinha U, Sinharay K, Saha S, Longkumer TA, Baul SN \& Pal SK. Thyroid disorders in polycystic ovarian syndrome subjects: a tertiary hospital based cross-sectional study from Eastern India. Indian Journal of Endocrinology and Metabolism 201317 304-309. (https://doi. org/10.4103/2230-8210.109714)

38 Yu Q \& Wang JB. Subclinical hypothyroidism in PCOS: impact on presentation, insulin resistance, and cardiovascular risk. BioMed Research International 20162016 2067087. (https://doi. org/10.1155/2016/2067087)

39 Janssen OE, Mehlmauer N, Hahn S, Offner AH \& Gartner R. High prevalence of autoimmune thyroiditis in patients with polycystic ovary syndrome. European Journal of Endocrinology 2004150 363-369. (https://doi.org/10.1530/eje.0.1500363)

40 Garelli S, Masiero S, Plebani M, Chen S, Furmaniak J, Armanini D \& Betterle C. High prevalence of chronic thyroiditis in patients with polycystic ovary syndrome. European Journal of Obstetrics, Gynecology, and Reproductive Biology 2013169 248-251. (https://doi. org/10.1016/j.ejogrb.2013.03.003)

41 Mitkov M, Nyagolova P \& Orbetzova M. [Thyroid stimulating hormone levels in euthyroid women with polycystic ovary syndrome]. Akusherstvo i ginekologiia 201554 10-15.

42 Petrikova J, Lazurova I, Dravecka I, Vrbikova J, Kozakova D, Figurova J, Vaczy Z \& Rosocha J. The prevalence of non organ https://ec.bioscientifica.com https://doi.org/10.1530/EC-18-0309 (c) 2018 The authors Published by Bioscientifica Ltd

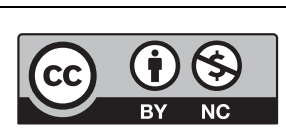

This work is licensed under a Creative Commons Attribution-NonCommercial 4.0 International License. 
specific and thyroid autoimmunity in patients with polycystic ovary syndrome. Biomedical Papers of the Medical Faculty of the University Palacky, Olomouc, Czechoslovakia 2015159 302-306. (https://doi. $\operatorname{org} / 10.5507 / \mathrm{bp} .2014 .062)$

43 Novais Jde S, Benetti-Pinto CL, Garmes HM, Jales RM \& Juliato CR. Polycystic ovary syndrome and chronic autoimmune thyroiditis. Gynecological Endocrinology 201531 48-51. (https://doi.org/10.3109/0 9513590.2014.958990)

44 Calvar CE, Bengolea SV, Deutsch SI, Hermes R, Ramos G \& Loyato M. [High frequency of thyroid abnormalities in polycystic ovary syndrome]. Medicina 201575 213-217.

45 Shapira Y, Agmon-Levin N \& Shoenfeld Y. Defining and analyzing geoepidemiology and human autoimmunity. Journal of Autoimmunity 201034 J168-J177. (https://doi.org/10.1016/j.jaut.2009.11.018)

46 Gaberscek S, Zaletel K, Schwetz V, Pieber T, Obermayer-Pietsch B \& Lerchbaum E. Mechanisms in endocrinology: thyroid and polycystic ovary syndrome. European Journal of Endocrinology 2015172 R9-R21. (https://doi.org/10.1530/EJE-14-0295)

47 Krassas GE, Poppe K \& Glinoer D. Thyroid function and human reproductive health. Endocrine Reviews 201031 702-755. (https://doi. org/10.1210/er.2009-0041)

48 Klecha AJ, Barreiro Arcos ML, Frick L, Genaro AM \& Cremaschi G. Immune-endocrine interactions in autoimmune thyroid diseases. Neuroimmunomodulation 200815 68-75. (https://doi. org/10.1159/000135626)

49 Quintero OL, Amador-Patarroyo MJ, Montoya-Ortiz G, RojasVillarraga A \& Anaya JM. Autoimmune disease and gender: plausible mechanisms for the female predominance of autoimmunity. Journal of Autoimmunity 201238 J109-J119. (https://doi.org/10.1016/j. jaut.2011.10.003)

50 Petrikova J, Lazurova I \& Yehuda S. Polycystic ovary syndrome and autoimmunity. European Journal of Internal Medicine 201021 369-371. (https://doi.org/10.1016/j.ejim.2010.06.008)

51 Hughes GC. Progesterone and autoimmune disease. Autoimmunity Reviews 201211 A502-A514. (https://doi.org/10.1016/j. autrev.2011.12.003)

52 Ruffilli I, Ferrari SM, Colaci M, Ferri C, Fallahi P \& Antonelli A. IP-10 in autoimmune thyroiditis. Hormone and Metabolic Research 201446 597-602. (https://doi.org/10.1055/s-0034-1382053)

53 Deng H, Li Z, Liu G, Li X, Chen Y, Zhang Y, Sun Y \& Fu J. Elevated serum interferon gamma-inducible protein-10 in women with polycystic ovary syndrome. Gynecological Endocrinology 201733 363-367. (https://doi.org/10.1080/09513590.2016.1269740)
54 Lim SS, Davies MJ, Norman RJ \& Moran LJ. Overweight, obesity and central obesity in women with polycystic ovary syndrome: a systematic review and meta-analysis. Human Reproduction Update 201218 618-637. (https://doi.org/10.1093/humupd/dms030)

55 Asvold BO, Bjoro T \& Vatten LJ. Association of serum TSH with high body mass differs between smokers and never-smokers. Journal of Clinical Endocrinology and Metabolism 200994 5023-5027. (https:// doi.org/10.1210/jc.2009-1180)

56 Muscogiuri G, Sorice GP, Mezza T, Prioletta A, Lassandro AP, Pirronti T, Della Casa S, Pontecorvi A \& Giaccari A. High-normal TSH values in obesity: is it insulin resistance or adipose tissue's guilt? Obesity 201321 101-106. (https://doi.org/10.1002/oby.20240)

57 Duntas LH \& Biondi B. The interconnections between obesity, thyroid function, and autoimmunity: the multifold role of leptin. Thyroid 201323 646-653. (https://doi.org/10.1089/thy.2011.0499)

58 Harpsoe MC, Basit S, Andersson M, Nielsen NM, Frisch M, Wohlfahrt J, Nohr EA, Linneberg A \& Jess T. Body mass index and risk of autoimmune diseases: a study within the Danish National Birth Cohort. International Journal of Epidemiology 201443 843-855. (https://doi.org/10.1093/ije/dyu045)

59 Aghini-Lombardi F, Antonangeli L, Martino E, Vitti P, Maccherini D, Leoli F, Rago T, Grasso L, Valeriano R, Balestrieri A, et al. The spectrum of thyroid disorders in an iodine-deficient community: the Pescopagano survey. Journal of Clinical Endocrinology and Metabolism 199984 561-566. (https://doi.org/10.1210/jcem.84.2.5508)

60 Hollowell JG, Staehling NW, Flanders WD, Hannon WH, Gunter EW, Spencer CA \& Braverman LE. Serum TSH, T(4), and thyroid antibodies in the United States population (1988 to 1994): National Health and Nutrition Examination Survey (NHANES III). Journal of Clinical Endocrinology and Metabolism 200287 489-499. (https://doi. org/10.1210/jcem.87.2.8182)

61 Tunbridge WM, Evered DC, Hall R, Appleton D, Brewis M, Clark F, Evans JG, Young E, Bird T \& Smith PA. The spectrum of thyroid disease in a community: the Whickham survey. Clinical Endocrinology 19777 481-493. (https://doi.org/10.1111/j.1365-2265.1977. tb01340.x)

62 Canaris GJ, Manowitz NR, Mayor G \& Ridgway EC. The Colorado thyroid disease prevalence study. Archives of Internal Medicine 2000 160 526-534. (https://doi.org/10.1001/archinte.160.4.526)

63 Singla R, Gupta Y, Khemani M \& Aggarwal S. Thyroid disorders and polycystic ovary syndrome: an emerging relationship. Indian Journal of Endocrinology and Metabolism 201519 25-29. (https://doi. org/10.4103/2230-8210.146860)

Received in final form $\mathbf{5}$ September 2018

Accepted 10 September 2018

Accepted Preprint published online 11 September 2018

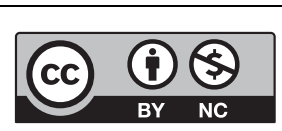

This work is licensed under a Creative Commons Attribution-NonCommercial 4.0 International License. 